\title{
Degradation of C.I. Reactive Orange 4 and its simulated dyebath wastewater by heterogeneous photocatalysis
}

\author{
M. Sameiro T. Gonçalves, * Elisa M.S. Pinto, Peter Nkeonye and Ana M.F. Oliveira- \\ Campos
}

Departamento de Química, Universidade do Minho, Gualtar, 4710-057 Braga, Portugal. Tel.: + 351-253-604386; fax: + 351-253-678983. E-mail: msameiro@quimica.uminho.pt

\begin{abstract}
The commercial azo dye C.I. Reactive Orange 4 in its reactive and hydrolysed forms can be efficiently photodegraded, using commercial samples of $\mathrm{TiO}_{2}$ as a photocatalyst. With UV light, aqueous solutions containing only dye and no dyebath additives are decolorised slightly more rapidly with Riedel-de-Häen $\mathrm{TiO}_{2}$ than with Degussa P-25 $\mathrm{TiO}_{2}$. The rate of decolorisation increases markedly with increasing $\mathrm{pH}$. Sunlight is also very effective as a light source. On the other hand, comparison experiments involving UV irradiation of hydrolysed and unhydrolysed Reactive Orange 4 in a simulated spent dyebath showed Degussa P-25 $\mathrm{TiO}_{2}$ to be significantly the more efficient catalyst, giving more than $90 \%$ decolorisation after 20 minutes.
\end{abstract}

Keywords: Photocatalytic oxidation; Titanium dioxide; Decolorisation; Reactive dye; C.I. Reactive Orange 4; Azo dye

\section{Introduction}

The textile industry is the largest consumer of colorants, using them in conjunction with a wide range of auxiliary chemicals for various dyeing, printing and finishing 
processes. Several dye application classes are utilised for cotton coloration, and of these reactive dyes are probably the most important. Irrespective of dye or fibre class, mill effluents are invariably deeply coloured by unabsorbed dyes, the extent of which varies according to the dye-fibre system. The treatment of industrial wastewaters in order to reduce visual colour and dissolved organic contaminants to meet increasing environmental demands has continued to attract the interest of research groups.

Most textile dyes are photolytically stable and refractory towards chemical oxidation [1] and these characteristics render them resistant towards decolorisation by conventional biochemical and physico-chemical methods. Alternative methods, such as activated carbon adsorption and dissolved air flotation, are not only costly, but result in phase transfer of pollutants. Hence there is considerable current interest in developing alternative and more cost-effective methods.

The combination of UV irradiation with photocatalysts such as $\mathrm{TiO}_{2}$ is one of such methods which has attracted considerable attention in recent years, due to its effectiveness in mineralization (i.e. conversion to inorganic species) of organic compounds [2-4]. This has included removal of dye pollutants from residual textile treatment waters [5-8]. Interest in this photocatalytic process stems mainly from its low cost, combined with the nontoxicity, insolubility, stability, high photoactivity of the catalyst $\left(\mathrm{TiO}_{2}\right)$. A further important advantage is the fact that the process can be powered by natural sunlight [9-13], thus reducing significantly the electrical power requirements and operating costs. It should be noted that with visible light, the photodegradation processes proceed by different routes, involving for example electron transfer from the excited state of the dye molecules adsorbed on the $\mathrm{TiO}_{2}$ surface into the conduction band of $\mathrm{TiO}_{2}$. Such processes are less efficient than those occurring with UV light. 
On the other hand, when aqueous $\mathrm{TiO}_{2}$ suspension is irradiated with light energy greater than the band gap energy of the pigment (hv>Eg $=3.2 \mathrm{eV} ; \quad \lambda<390 \mathrm{~nm}$ ), conduction band electrons $\left(\mathrm{e}^{-}\right)$and valence band holes $\left(\mathrm{h}^{+}\right)$are formed. The photogenerated electrons react with adsorbed molecular $\mathrm{O}_{2}$, reducing it to superoxide radical anion $\mathrm{O}_{2}{ }^{--}$, and the photogenerated holes can oxidize either the organic molecules directly, or can oxidise $\mathrm{OH}^{-}$ions and water molecules adsorbed on the $\mathrm{TiO}_{2}$ surface to $\mathrm{OH}$ radicals [2]. These will act as strong oxidizing agents that can easily attack any organic molecules adsorbed on, or located close to, the surface of the catalyst, thus leading to their complete degradation into small inorganic species (eq. 1-5) (Fig. 1).

$$
\begin{aligned}
& \mathrm{TiO}_{2}+\mathrm{hv} \longrightarrow \mathrm{TiO}_{2}\left(\mathrm{~h}^{+}+\mathrm{e}^{-}\right) \\
& \mathrm{O}_{2}+\mathrm{e}^{-} \longrightarrow \mathrm{O}_{2}^{\cdot-} \\
& \mathrm{h}^{+}+\mathrm{H}_{2} \mathrm{O} \longrightarrow \mathrm{H}^{+}+\mathrm{OH}^{\cdot} \\
& \mathrm{OH}^{\cdot}+\mathrm{RH}+\mathrm{H}^{\cdot} \\
& \mathrm{R}^{\cdot}+\mathrm{O}_{2} \longrightarrow \mathrm{ROO} \longrightarrow \longrightarrow \mathrm{CO}_{2}
\end{aligned}
$$

Fig. 1. Mechanism of the $\mathrm{TiO}_{2}$ - catalysed UV oxidative degradation of organic species

Our previous studies on photocatalytic decolorisation of dyes [14] have now been extended to include the important reactive dye C.I. Reactive Orange 4 (Fig. 2). This is a monoazo dichlorotriazinyl reactive dye [ICI (Zeneca) Procion $M X$ type] that can be considered representative of the class. As a dichlorotriazinyl dye, it has a high reactivity towards nucleophiles, and readily undergoes dyebath hydrolysis [15]. It is applied to cotton at about $30^{\circ} \mathrm{C}$ in the presence of common salt, and base (final $\mathrm{pH} 10.5-11.0$ ), and other auxiliary products are generally present to aid dyeing. Dye fixation onto the fibre occurs by 
nucleophilic displacement of the reactive triazinyl chlorine atoms by ionised glycosidic hydroxyl groups of the cellulose, resulting in covalent bonding of the dye to the fibre by ether bonds. However, hydroxide ions in the dyebath can compete with the cellulose, so causing hydrolysis of the dye without fixation [16, 17]. With the Procion $M X$ dyes, the hydrolysed unfixed dye can amount to as much as $15-40 \%$ of the total applied [18], and this poses a major problem with highly coloured dyebath effluent. The present paper examines the efficiency of photocatalysis as a means of decolorising C.I. Orange 4, both in water alone and in a simulated dyebath effluent, and for this purpose compares the relative efficacy of two commercially available photocatalysts, namely Degussa P-25 and Riedelde-Häen $\mathrm{TiO}_{2}$.<smiles>CN(c1ccc2cc(S(=O)(=O)O[Na])c(N=Nc3cc(S)c4cccc(S(=O)(=O)O)c4c3)c(O)c2c1)c1nc(Cl)nc(Cl)n1</smiles>

Fig. 2. Chemical structure of C.I. Reactive Orange 4.

\section{Experimental}

\subsection{Materials}

A commercial sample of C.I. Reactive Orange 4 was used in this study, without further purification. The photocatalysts employed were technical grade $\mathrm{TiO}_{2}$ Riedel-deHäen and $\mathrm{TiO}_{2}$ Degussa P-25. Additives for the preparation of the simulated dyebath effluent were from Bayer (Erkantol AS) and Sandoz (Sandopan CBH), and all other chemicals were of technical grade. 
Adjustment of $\mathrm{pH}$ of the dye solutions prior to degradation was carried out with $6 \mathrm{M}$ sodium hydroxide or $0.1 \mathrm{M}$ perchloric acid.

Chemical Oxygen Demand (COD) measurements were carried out with a specific commercial reagent low range kit (HACH DR/2000).

\subsection{Apparatus}

UV-vis spectra were recorded on a Hitachi U-2000 spectrophotometer.

UV-Irradiation experiments were carried out using an immersion reactor fitted with a medium pressure $400 \mathrm{~W} \mathrm{Hg}$ vapour lamp (Photochemical Reactors, Applied Photophysics, APQ 40). For sunlight exposure, a Pyrex flask of $22.5 \mathrm{~cm}$ internal diameter was used, and the light intensity was measured as 28000-30000 Lux, using a Testo 545 lightmeter.

\subsection{Irradiation and analysis of dye solutions}

Three types of dye solution were investigated, all at a dye concentration of $38 \mathrm{mg} / \mathrm{l}$ : (a) the unhydrolysed dye in water alone; (b) the unhydrolysed dye in a simulated dyebath liquor; (c) hydrolysed dye in the same simulated dyebath liquor. The composition of the simulated effluent and the functions of the additives in the mixture are described in Table 1. A solution of unhydrolysed dye in this medium was prepared by mixing the components at room temperature and used as such. Conversion of the reactive dye into its hydrolysed form was ensured by heating the solution near the boiling point for 5 minutes and allowing it to cool overnight. 
Table 1: Composition of the simulated dyebath effluent

\begin{tabular}{lll}
\hline Component & $\begin{array}{l}\text { Concentration } \\
(\mathrm{mg} / \mathrm{l})\end{array}$ & Function \\
\hline $\mathrm{Dye}$ & 38 & -- \\
$\mathrm{NaCl}$ & $1.2 \times 10^{3}$ & Promotes exhaustion of the dye onto cotton \\
$\mathrm{Na}_{2} \mathrm{CO}_{3}$ & 5 & Adjustment of the starting alkaline pH (8.8-9.3). \\
$\mathrm{NaOH}$ & 5 & Adjustment of the final dyeing pH (10.5-11.0) to cause \\
& & further ionization of the cellulose and dye-fibre \\
& 10 & reaction. \\
Erkantol AS & Lubrificant for fibre; minimizes creases and rope \\
& marks. \\
Sandopan CBH & 20 & Detergent for washing off. \\
EDTA & 10 & Removes unwanted metal ions in the dyebath water. \\
$\mathrm{CH}_{3} \mathrm{CO}_{2} \mathrm{H}$ & 10 & Reduces the alkalinity of the effluent. \\
\hline
\end{tabular}

After addition of the required amount of photocatalyst, the dye solutions were magnetically stirred in the dark for 30 minutes to equilibrate. No adsorption of the dye on the catalyst (i.e. no change in the solution absorbance) was observed to occur during this period. Irradiation was then commenced and the dispersion was kept stirred throughout the duration of the experiment. Aliquots were removed at intervals and, after centrifugation and/or filtration through a $0.20 \mu \mathrm{m}$ syringe filter, the absorbance was read at $482 \mathrm{~nm}$ on a Hitachi UV-2000 spectrophotometer. Catalyst concentration was studied at $1 \mathrm{~g} / \mathrm{l}$ and 360 $\mathrm{mg} / \mathrm{l}$. For the rate determinations, calibration curves for the dye in water were obtained at its $\lambda_{\max }(482 \mathrm{~nm})$ at $\mathrm{pH}$ values of 10,13 and 5.6 ( $\mathrm{pH}$ of distilled water).

Blank experiments were also conducted (without $\mathrm{TiO}_{2}$ ) under sunlight and UV light irradiation. 


\subsection{Kinetic analysis}

In all the experiments the disappearance of the dye during the first 10 minutes of irradiation followed pseudo first order kinetics, as may be seen from the data of Table 2 . Initial decolorisation rate constants were determined from the slope of $\ln (\mathrm{Co} / \mathrm{C})$ vs $\mathrm{t}(\mathrm{min}$. plots, where $\mathrm{Co}$ and $\mathrm{C}$ are the dye concentrations at zero time and time $\mathrm{t}$, respectively. The value of $\mathrm{Co} / \mathrm{C}$ was taken as the ratio $\mathrm{Ao} / \mathrm{A}$, i.e. the absorbance value of the solution at $\lambda_{\max }$ at zero time divided by the absorbance at time $t$.

Table 2: Pseudo first order rate constants for the decolorisation of solutions of Reactive Orange 4 (concentration $38 \mathrm{mg} / \mathrm{l}$ dye powder). (UV irradiation except where noted).

\begin{tabular}{lcccc}
\hline Solution $^{\mathrm{a}}$ & $\begin{array}{c}{\left[\mathrm{TiO}_{2}\right](\mathrm{type}){ }^{\mathrm{b}}} \\
\mathrm{g} / \mathrm{l}\end{array}$ & $\mathrm{pH}$ & $\mathrm{r}^{2 \mathrm{c}}$ & $\mathrm{k}\left(\mathrm{min}^{-1}\right)^{\mathrm{d}}$ \\
\hline Aqueous & $0.36(\mathrm{P} 25)$ & 5.6 & 0.9993 & 0.0702 \\
Aqueous & $0.36(\mathrm{P} 25)$ & 10 & 0.9916 & 0.0909 \\
Aqueous & $0.36(\mathrm{P} 25)$ & 13 & 0.9363 & 0.3281 \\
Aqueous & $1.00(\mathrm{P} 25)$ & 10 & 0.9790 & 0.1306 \\
Aqueous & $1.00(\mathrm{RH})$ & 10 & 0.9985 & 0.0952 \\
Aqueous & $1.00(\mathrm{P} 25)$ & 10 & 0.9958 & 0.0605 \\
Dyebath hydrolysed & $1.00(\mathrm{P} 25)$ & 10 & 0.9740 & 0.0765 \\
Dyebath hydrolysed & $1.00(\mathrm{RH})$ & 10 & 0.9980 & 0.0234 \\
Dyebath unhydrolysed & $1.00(\mathrm{P} 25)$ & 10 & 0.9052 & 0.0202 \\
Dyebath unhydrolysed. & $1.00(\mathrm{RH})$ & 10 & 0.9952 & 0.0159
\end{tabular}

a "Aqueous" refers to a solution of the dye in water with no other additives

${ }^{\mathrm{b}} \mathrm{P} 25=$ Degussa P-25; RH = Riedel-de- Häen

${ }^{\mathrm{c}}$ Correlation coefficient of the straight line.

${ }^{\mathrm{d}}$ Pseudo first order rate constant determined for the first 10 minutes of irradiation.

${ }^{\mathrm{e}}$ Sunlight irradiation 


\section{Results and Discussion}

\subsection{Photocatalytic decolorisation of Reactive Orange 6 alone in water.}

Experiments were first carried out using an aqueous solution of the unhydrolysed dye alone, without any dyebath additives, using a $\mathrm{pH}$ value of 10 . As shown in Fig. 3, the Riedel-de-Häen catalyst was found to be marginally superior to the Degussa P-25 product for effecting decolorisation of the solutions. Also shown in Fig. 3 is the rate of decolorisation of a similar solution, using $\mathrm{TiO}_{2}$ Degussa P-25 with sunlight irradiation. It can be seen that the process is only slightly slower than for the UV irradiated solutions, with $\mathrm{ca} 45 \%$ loss of colour after only 10 minutes exposure, rising to $88 \%$ after a further 50 minutes. Relevant kinetic data are summarised in Table 2.

Control experiments, using UV or solar irradiation in the absence of catalyst, showed no loss of colour after 60 minutes exposure, confirming the critical role played by the $\mathrm{TiO}_{2}$ catalyst in dye degradation.

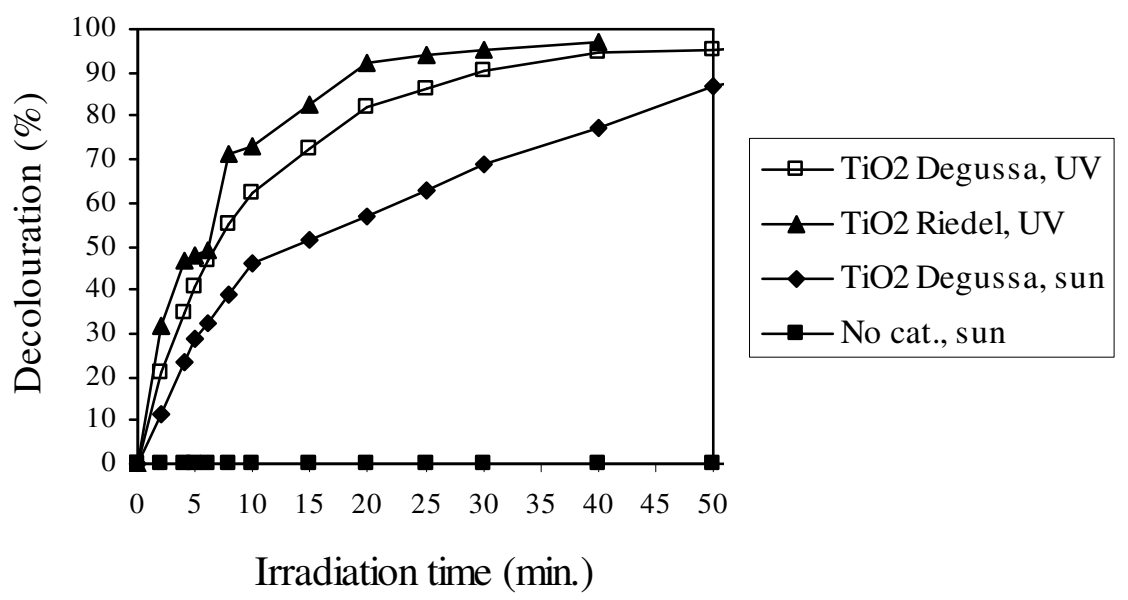

Fig. 3. Influence of catalyst and irradiation source on the rate of decolorisation of solutions of Reactive Orange 4 in water alone $\left(\mathrm{pH} 10, \mathrm{TiO}_{2} 1 \mathrm{~g} / \mathrm{l}\right)$.

The $\mathrm{pH}$ dependence of the rate of decolorisation for the dye-only solutions was next examined by carrying out UV-irradiated experiments with a lower concentration of the 
$\mathrm{TiO}_{2}$ Degussa P-25 catalyst $(360 \mathrm{mg} / \mathrm{l})$, at $\mathrm{pH}$ values of $5.6,10$, and 13 . The kinetic results are summarised in Fig. 4, and show that even at this lower $\mathrm{TiO}_{2}$ concentration, decolorisation of the reactive dye is rapid, and the reaction rate increases with $\mathrm{pH}$. The acceleration at high $\mathrm{pH}$ may be due to the presence of higher proportion of hydrolysed forms of the dye, and/or the higher concentration of hydroxide ions, leading to the photogeneration of more of the reactive hydroxyl radical species. When parallel experiments were carried out with the Riedel-de-Häen catalyst, a similar $\mathrm{pH}$ dependence was observed, and for example at $\mathrm{pH} 5.6$ it required a irradiation time of 2.5 hours to achieve $90 \%$ decolorisation, whereas at $\mathrm{pH} 13$ it required only 1.5 hours to achieve the same effect.

Relevant first order rate constants are indicated in Table 2.

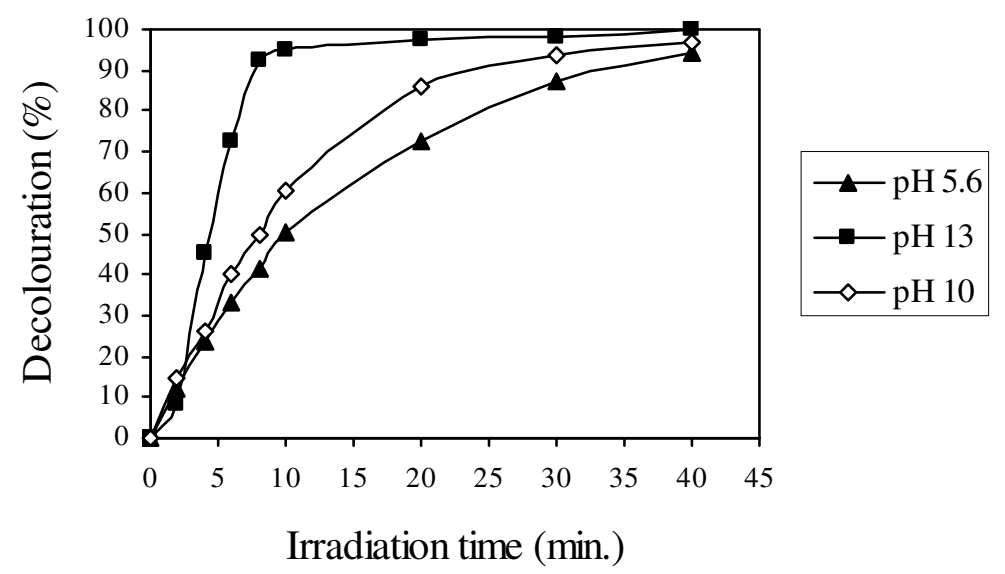

Fig. 4. Influence of pH on UV-induced decolorisation of dye-only solution in the presence of Degussa P-25 $\mathrm{TiO}_{2}(360 \mathrm{mg} / \mathrm{l})$.

In advanced oxidation processes, such us ozone treatment, $\mathrm{UV} / \mathrm{H}_{2} \mathrm{O}_{2}$ and irradiation in the presence of $\mathrm{TiO}_{2}$ hydroxyl radicals are formed. It may be assumed that intermediates involved in these three types of treatment may be similar. In this work there was no attempt 
to identify intermediates or final products. However, previous photocatalytic $\left(\mathrm{TiO}_{2}\right)$ work on dyes containing triazinyl [19] units which was followed by GC-MS analyses concluded that nitrogen was eliminated, benzene and naphthalene rings were broken and fragments containing the triazine system were identified as intermediates. Colonna et al. [20] in studies with $\mathrm{UV} / \mathrm{H}_{2} \mathrm{O}_{2}$ on dyes containing anthraquinone and sulfonated naphthol rings suggest nitrogen is evolved at an earlier stage, from the azo group and the sulphonic groups were replaced by hydroxyl groups forming polyhydroxylated species. Continuing photoxidation may lead to quinone type compounds and later to aromatic ring cleavage with formation of diacids. Studies by Zhang et al. [21] also on triazine containing dyes using ozonation gave as the main degradation products sulphate, nitrate, formate and oxalate. When the oxidation is complete organic compounds end up as $\mathrm{CO}_{2}$. We may then write a general type equation, considering the complete oxidation of the dye:

Dye $+\mathrm{OH} \rightarrow$ intermediates $+\mathrm{N}_{2}$

Intermediates $+\mathrm{OH}^{-} \rightarrow \mathrm{CO}_{2}, \mathrm{H}_{2} \mathrm{O}, \mathrm{NO}_{3}^{-}, \mathrm{Cl}^{-}, \mathrm{SO}_{4}{ }^{2-}$

\subsection{Photodecolorisation of simulated dyebath effluent}

In an attempt to relate our present study to the real situation arising with effluent from the commercial dyeing of cotton with reactive dyes, it was decided to formulate a simulated spent dyebath and to test its response to photocatalytic degradation.

The rinsing, soaping $\left(98^{\circ} \mathrm{C}, 15-30\right.$ minutes) and acidic neutralisation processes which follow the reactive dyeing of cotton result in a considerable dilution of the dyehouse effluent [1]. Two types of spent dyebath effluent were investigated. One of them contained the fully hydrolysed dye with relevant additives, while the other one contained essentially 
unhydrolysed dye with the same additives. In the latter case, solutions were made up in cold water and were used the same day to minimise hydrolysis. In the former case, the solutions were boiled and kept for several hours to ensure complete hydrolysis of the chlorotriazinyl groups. The simulated dyebath effluents containing either hydrolysed or unhydrolysed dye both gave a $\mathrm{pH}$ reading of $c a 10$. The results for the photocatalysed decolorisation reactions are presented in Fig. 5, and show that, for both the Degussa P-25 and Riedel-de-Häen catalyst types, at $1 \mathrm{~g} / \mathrm{l}$ concentration, the solutions containing hydrolysed dye decolorised faster than those containing unhydrolysed dye. In addition, the Degussa P-25 catalyst was the more efficient of the two, showing more than $90 \%$ decolorisation after 20 minutes irradiation.

Relevant kinetic parameters are summarised in Table 2.

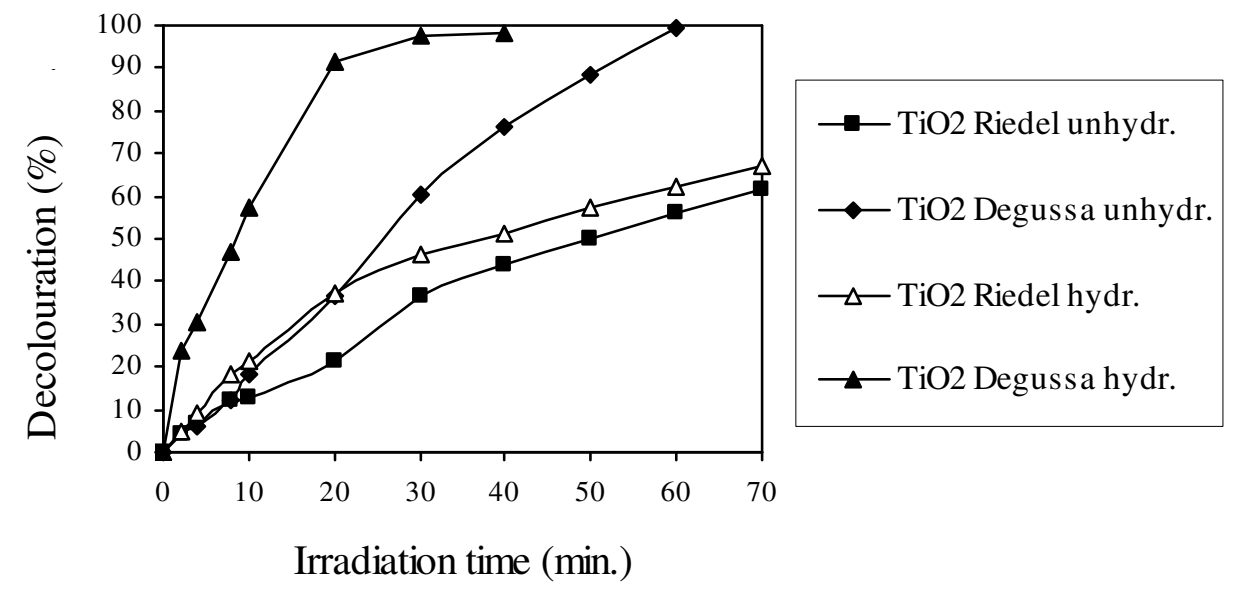

Fig. 5. Influence of catalyst type on decolorisation of simulated dyebath effluent $\left(\mathrm{TiO}_{2} 1\right.$ $\mathrm{g} / \mathrm{l})$. 


\subsection{COD decrease}

COD decreases of 80 and $94 \%$ were observed after one hour of UV or solar irradiation, respectively, for experiments with solutions of the dye only and $\mathrm{TiO}_{2}$ Degussa P-25 (1 g/l), at pH 10. Under similar UV irradiation conditions, at pH 5.6 two hours were needed to obtain a $70 \%$ decrease. This is consistent with the observed enhancement of photodecolorisation with increasing $\mathrm{pH}$.

\section{Conclusions}

We have shown that photocatalysis using UV light or sunlight in conjunction with $\mathrm{TiO}_{2}$ is a promising method for degrading C.I. Reactive Orange 4 either alone in water, or in its hydrolysed and unhydrolysed forms in spent dyebath liquor. The rate of decolorisation is higher for hydrolysed dye than for unhydrolysed dye in a simulated dyebath effluent. At the same $\mathrm{pH}$, the simulated dyebath effluent is decolorised at a somewhat slower rate than solutions of the dye in water alone, presumably due to competition from the organic additives in the dyebath. For the dye-only solutions, the Degussa P-25 catalyst was more efficient at decolorisation than the Riedel-de-Häen catalyst when using sunlight as the light source. These results are very promising, and further investigations are warranted to examine the commercial potential of the technique as an economic means of treating dyehouse effluent.

\section{Acknowledgements}

PRAXIS XXI/2/2.1/44/94, FEDER. Also thanked are: Ahmadu Bello University, Zaaria, Nigeria for a sabbatical leave to P. Nkeonye and Degussa Portuguesa for a gift of $\mathrm{TiO}_{2}$ Degussa P-25 to be used in our experiments. 


\section{References}

[1] Arslan I, Balcioglu IA. Degradation of Remazol Black B dye and its simulated dyebath wastewater by advanced oxidation processes of heterogeneous and homogeneous media. Color Technol 2001;117:38-42.

[2] Hoffmann MR, Martin ST, Choi W, Banehmann DW. Environmental applications of semiconductor photocatalysis. Chem Rev 1995;95:69-96.

[3] Legrini O, Oliveros E, Braun AM. Photochemical processes for water treatment. Chem Rev 1993;93:671-698.

[4] Vorontsov VA, Dubovitskaya. Selectivity of photocatalytic oxidation of gaseous ethanol over pure and modified $\mathrm{TiO}_{2}$. Journal of Catalysis 2004;221:102-109.

[5] Arslan I, Balcioglu IS, Bahnemann DW. Advanced chemical oxidation of reactive dyes in simulated dyehouse effluents by ferrioxalate-Fenton/UV-A and $\mathrm{TiO}_{2} / \mathrm{UV}-\mathrm{A}$ processes. Dyes and Pigments 2000;47:207-218.

[6] Hachem C, Bocquillon F, Zahraa O, Bouchy M. Decolourization of textile industry wastewater by the photocatalytic degradation process. Dyes and Pigments 2001;49:117-125.

[7] Saquib M, Muneer M. Titanium dioxide mediated photocatalysed degradation of a textile dye derivative, acid orange 8 , in aqueous suspensions. Desalination 2003;155:255-263.

[8] Saquib M, Muneer M. $\mathrm{TiO}_{2}$-mediated photocatalytic degradation of a triphenylmethane dye (gentian violet), in aqueous suspensions. Dyes and Pigments 2003;56:37-49. 
[9] Saquib M, Muneer M. Semiconductor mediated photocatalysed degradation of an anthraquinone dye, Remazol Brilliant Blue $\mathrm{R}$ under sunlight and artificial light source. Dyes and Pigments 2002;53:237-249.

[10] Augugliaro V, Baiocchi C, Prevot AB, García-Lopez E, Loddo V, Malato S, Marcí G, Palmisano L, Pazzi M, Pramauro E. Azo-dyes photocatalytic degradation in aqueous suspension of $\mathrm{TiO}_{2}$ under solar irradiation. Chemosphere 2002;49:1223-1230.

[11] Stylidi M, Kondarides DI, Verykios XE. Pathways of solar light-induced photocatalytic degradation of azo dyes in aqueous $\mathrm{TiO}_{2}$ suspensions. Applied Catalysis B: Environmental 2003;40:271-286.

[12] Stylidi M, Kondarides DI, Verykios XE. Visible light-induced photocatalytic degradation of Acid Orange 7 in aqueous $\mathrm{TiO}_{2}$ suspensions. Applied Catalysis B: Environmental 2004;47:189-201.

[13] Chen Y, Wang K, Lou L. Photodegradation of dye pollutants on silica gel supported $\mathrm{TiO}_{2}$ particles under visible light irradiation. Journal of Photochemistry and Photobiology A: Chemistry 2004;163:281-287.

[14] Gonçalves MST, Oliveira-Campos AMF, Pinto EMMS, Plasência PMS, Queiroz MJRP. Photochemical treatment of solutions of azo dyes containing $\mathrm{TiO}_{2}$. Chemosphere 1999;39(5):781-786.

[15] Burkinshaw SM. In: Waring DR, Hallas G, editors. Chemistry and application of dyes. New York: Plenum Press, 1990. p. 317-332.

[16] Rhys P, Zollinger H. In: The Theory of coloration of textiles. Bradford, Dyers Co. Publ. Trust, 1975. p. 326-358

[17] Rattee ID. In: Venkataraman, editor. The Chemistry of synthetic dyes, Vol. III. London: Academic Press, 1978. 
[18] Allen RLM. Colour chemistry. London: Nelson \& Sons, 1971.

[19] Daoxin Y, Huasheng X, Shugui D. Photocatalytic decolourization of reactive dyes. Journal Environmental Sciences (China) 1992;4(1):97-105.

[20] Colonna GM, Caronna T, Marcandali B. Oxidative degradation of dyes by ultraviolet radiation in the presence of hydrogen peroxide. Dyes and Pigments 1999; 41:211-220.

[21] Zhang F, Yediler A, Liang X, Kettrup A. Effects of dye additives on the ozonation process and oxidation by-products. A comparative study using hydrolyzed C.I. Reactive Red 120. Dyes and Pigments 2004;60:1-7. 